Supplement of The Cryosphere, 13, 3405-3412, 2019

https://doi.org/10.5194/tc-13-3405-2019-supplement

(C) Author(s) 2019. This work is distributed under

the Creative Commons Attribution 4.0 License.

(c) (1)

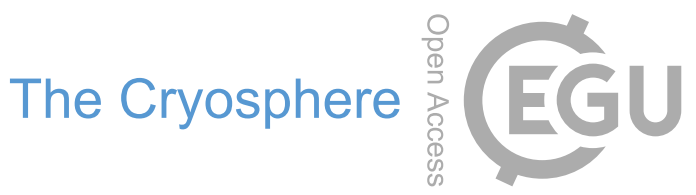

Supplement of

\title{
Brief communication: Rare ambient saturation during drifting snow occurrences at a coastal location of East Antarctica
}

\section{Charles Amory and Christoph Kittel}

Correspondence to: Charles Amory (charles.amory@uliege.be)

The copyright of individual parts of the supplement might differ from the CC BY 4.0 License. 


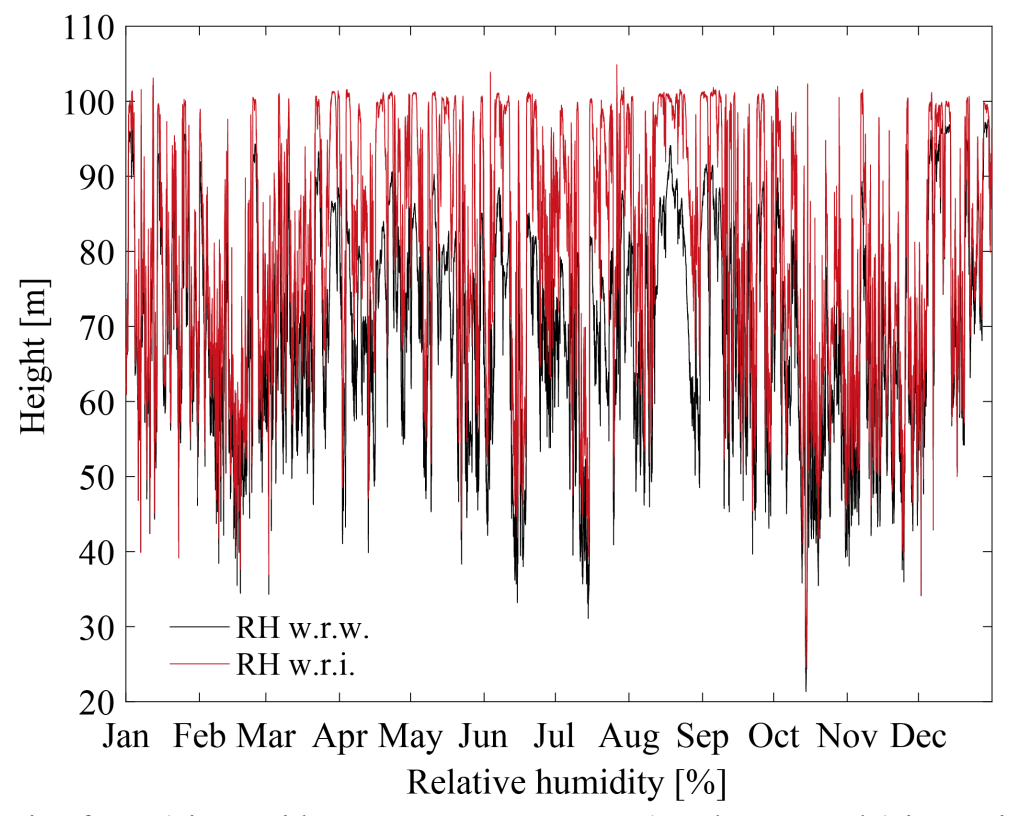

Figure S1. Timeserie of raw (given with respect to water; w.r.w.) and converted (given with respect to ice; w.r.i.) $\mathrm{RH}$ values at $2 \mathrm{~m}$ height showing the regular occurrence of $\mathrm{RH}>100 \%$ due to limitations of the Goff-Gratch formulae used in the conversion. 


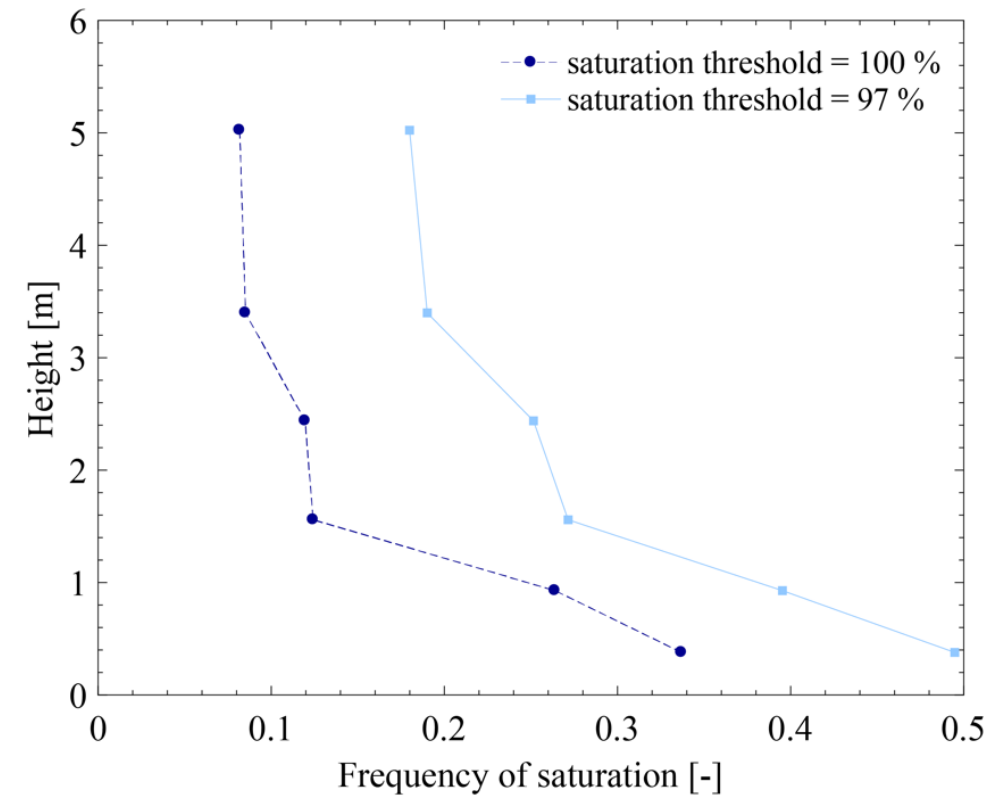

Figure S2. Frequency of saturation in drift conditions at each measurement level assuming that saturation is reached at $100 \%$ (dashed line) and $97 \%$ (solid line). Yearly average instrument heights are used. 